\title{
The analysis of the state of a turned surface with the use of its image
}

\author{
A. Zawada-Tomkiewicz \& B. Storch \\ Koszalin University of Technology, Poland
}

\begin{abstract}
This paper presents the influence of cutting parameters on the machined surface in turning. Machined surface geometrical features were analyzed in the aspect of four different tool geometries. The analyzed machined surfaces possessed definitely unlike features. The tool with rounded cutting wedge created a machined surface in a form of a thread. For the greater tool nose radius the machined surface was smoother and contained fewer features of the thread. In wiper geometry the machined surface was burnished by the additional radii. In modified geometry, in a form of artificial wear, the machined surface was very smooth with visible material side flow. The aspect of the machined surface creation was discussed for each different geometry. The machined surface after turning was analyzed with the use of surface image data. Turned surface images were indicated dependent on feed rate and tool geometry.

Keywords: turning, tool geometry, machined surface, image analysis.
\end{abstract}

\section{Introduction}

Machined surfaces consist of irregularities and defects, such as tool marks and scratches. After turning the resultant surface is created by two-way interaction between the surface and the tool wedge. All the turned surfaces contain the dominant feed component disturbed by vibrations, tool wear and cutting parameters $[5,6]$. The use of turning as a finishing process is often limited by surface quality requirements.

The developments in cutting tool materials and geometries have significantly increased the potential for industrial applications of turning as a finishing process. To achieve high surface quality, a good understanding of the effects of process parameters on surface quality is necessary $[2,3]$. 
Surface quality in turning is affected by many factors. One of the most important is tool nose radius. A large nose radius distributes the cut along a greater length, providing better heat dissipation. A large nose radius ensures also better parameters of surface finish. The idea of greater nose radius was applied in the creation of the wiper geometry. Wiper inserts feature additional radii behind the tool nose that are kept in contact with the workpiece after the initial cut. This burnishes peaks and results in a smoother surface finish. Increase of feed per revolution for wiper geometries enables the achievement of the same surface finish as with a standard radius turning insert with a small feed. Wiper geometries require large depths of cut and high feed rates to work correctly [1].

For non-wiper geometries the low roughness can be achieved only at low feed rates. But a very small feed rate led to more material side flow on the machined surface and to a deterioration of the surface quality [6]. The improvement in surface roughness in such circumstances was achieved by applying a tool at a certain degree of wear $[3,7,8]$. For finishing operation of turning the artificial wear land on the tool nose was introduced with the patent of Borys Storch (1998). The increased contact zone and strengthening of tool corner were achieved by avoidance of the first initial phase of accelerated wear. For tool with modified geometry the linear increment of wear land was observed with improvement in surface finish parameters $[4,7]$.

The main aim of the study was the assessment of the machined surface produced in turning, keeping different cutting conditions and then the comparison of machined surfaces with the use of optical imaging. The surface was illuminated with different lightings and the mechanisms of the creation of these surfaces were revealed. The replication of the tool tip profile on the machined surface was explored. The machined surface images confirmed the variability of the surface with the great impact of the cutting tool geometry.

\section{Experimental details}

\subsection{Material specification and specimen preparation}

In this study, steel C45 (EN 10250-2:2001) with 137 HB was used as workpiece material. It was selected because of its wide range of applications in industry. Workpieces were received as cylindrical bars with an initial diameter of $26 \mathrm{~mm}$.

\subsection{Turning tools and the procedure of the turning process}

Cutting parameters were selected according to the tool manufacturer recommendations. The insert type and feed rate were determined as process variables. Four constructions of cutting tool geometry were considered in this study, which were described as wiper geometry, modified geometry and rounded tool nose featuring two different radii (Table 1). Tool nose geometry was considered as a key factor affecting insert strength and machined surface finish. Using a large nose radius makes the cut to be distributed along a greater length, providing better heat dissipation and improving tool life. Two different tool nose 
radii were applied $-0.8 \mathrm{~mm}$ and $0.4 \mathrm{~mm}$ (Insert 3 and Insert 4). The wiper geometry (Insert 1) features additional radii behind the tool nose that are kept in contact with the workpiece after the initial cut. The modified geometry in a way of artificial wear on the tool nose (Insert 2) increases the contact zone and strengthening of tool corner by avoidance of first initial phase of accelerated wear.

Table 1: $\quad$ Turning tool geometries.

\begin{tabular}{|c|c|c|c|}
\hline $\begin{array}{c}\text { Insert 1 - wiper } \\
\text { TNMX 160408WF }\end{array}$ & $\begin{array}{c}\text { Insert 2 - modified } \\
\text { TNMG 160408 PF } \\
\mathrm{KE}_{\text {artificial }}=0.02 \mathrm{~mm}\end{array}$ & $\begin{array}{c}\text { Insert 3 - rounded } \\
\text { TNMG 160408 PF }\end{array}$ & $\begin{array}{c}\text { Insert 4 - rounded } \\
\text { TNMG 160404 PF }\end{array}$ \\
\hline & & & \\
\hline
\end{tabular}

Before each experiment, the workpiece was turned with a new tool to preserve the same starting conditions. Feed rate was chosen to be $0.1,0.2$ and 0.3 $\mathrm{mm} / \mathrm{rev}$ with cutting speed of $100 \mathrm{~m} / \mathrm{min}$ and depth of cut equal to $1.0 \mathrm{~mm}$.

\subsection{Surface roughness measurements}

After the process of turning the measurements of surface roughness were performed. The surface roughness was measured using the optical method with the use of surface roughness Taylor-Hobson CC16000 instrument with 59x lens and stylus profilometer HOMMELWERKE T2000E. The cut-off and sampling length for optical measurement was taken as $0.388 \mathrm{~mm}$ and stylus measurement was taken as $0.8 \mathrm{~mm}$. On each specimen, nine surface roughness measurements were made along the machined surface and an average of these values was taken as a response variable.

For rounded cutting nose the machined surface after turning was the result of kinematic-geometrical pass of the tool.

For wiper tool geometry, additional radii smothered the traces after each pass of the turning tool. In this way the created machined surface after turning was also initially burnished. The shapes of machined surface profiles were combined in Figure 1. For wiper geometry the main shape of turned surface was almost lost. For other geometries the feed component was easier to explore. The machined surface for modified geometry looks the most promising because it is reflective and fine.

Images of ordinate values of the surfaces, combined in Figure 2, show the distribution of irregularities. In this presentation the machined surface for wiper 
geometry is significantly different from other surfaces for all the feed rates. It is a set of flat overlapping surfaces. The small deep holes can be distinguished between the surfaces. The machined surface for modified geometry is the smoothest.

When the rounded cutting tools were applied, then the vertical parameters were strictly associated with feed rate. Only for small feed rate the surface roughness $\mathrm{Ra}$ parameter was smaller than $2 \mu \mathrm{m}$. For wiper and modified geometry of the tool the mean roughness of the machined surface for all the feed rates was not greater than $2 \mu \mathrm{m}$. The machined surface for modified geometry for all the feed rates indicated the features of being reflective and smooth.

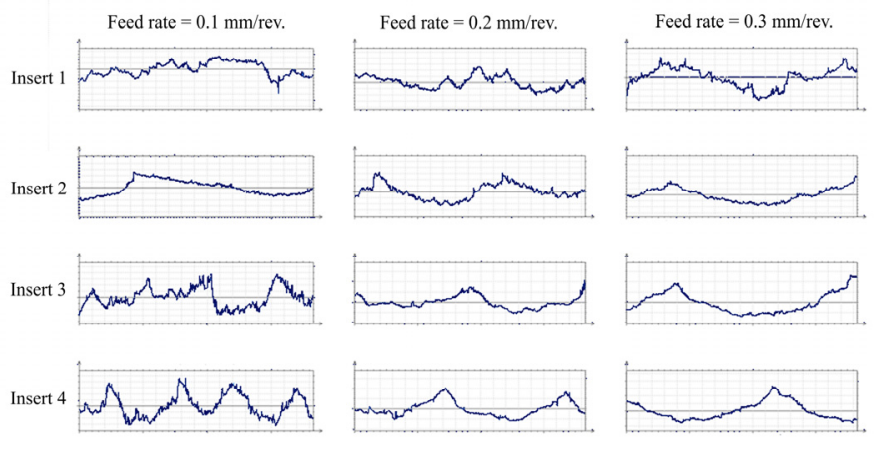

Figure 1: The shape of machined surface profile (CC16000) - ordinate values (vertical axis) in a function of $388 \mu \mathrm{m}$ definition length (horizontal axis).

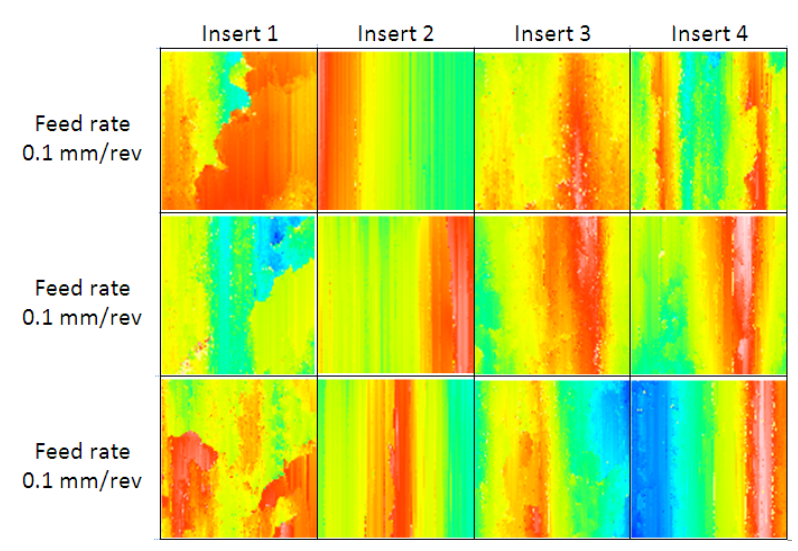

Figure 2: The shape of machined surface (CC16000) - ordinate values $150 \mu \mathrm{m}^{2}$. 


\subsection{Measurement system for optical imaging}

The vision system for turned surface observation was based on a computer with a frame-grabber card, a digital camera, lenses, a stand for a camera with movable worktable and a lighting system (Figure 4a). Four different ways of observing the machined surface were proposed (Fig. 4b, 5).

a)

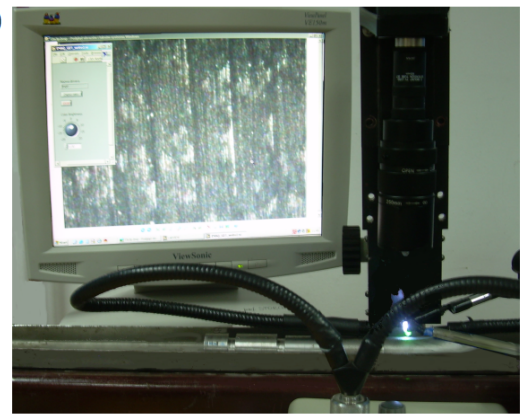

b)

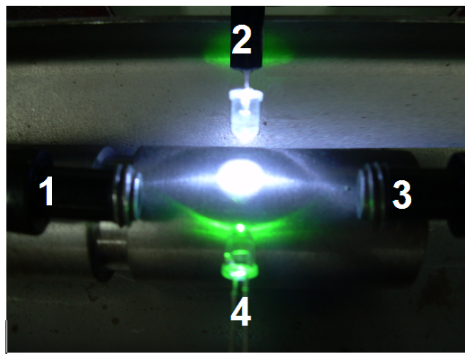

Figure 3: $\quad$ Surface roughness $\mathrm{Ra}$ parameter after the turning operation T2000E with definition length of $0.8 \mathrm{~mm}$.

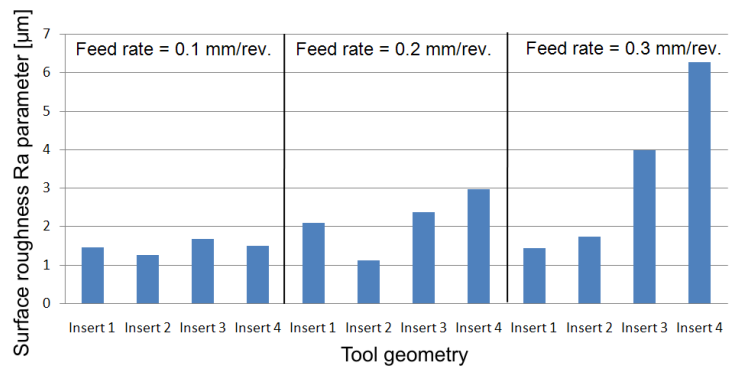

Figure 4: a) Vision system for machined surface image acquisition, b) lighting configuration for the surface illumination.

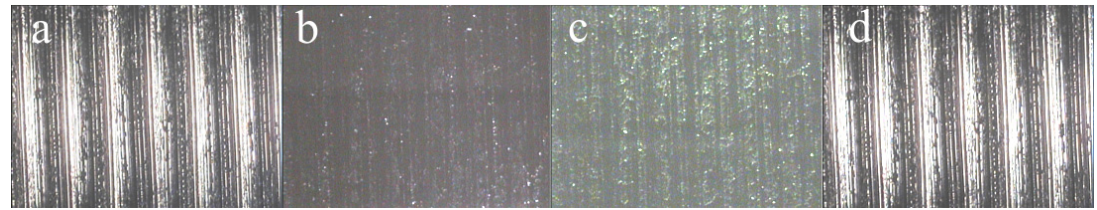

Figure 5: $\quad$ Machined surface image (Fig. 4b): two-sided lighting with the use of halogen - (1-3). One-sided lighting with the use of blue LED (2), one-sided lighting with the use of green LED - (4). Four-sided lighting with the use of halogen and LED - (1-2-3-4). 
The main way of illumination of machined surface after the turning process was the two-sided lighting system based on a halogen white light. It revealed the main shape of irregularities, which were directional with periodic marks after the tool run (Fig 5a). Irrespective of the direction of lighting, the illumination of the surface along the traces presented a texture, which was weak and full of small pale dots (Fig. 5b, 5c). Utilisation of all the sources of lighting, presented in Figure 5d, was almost without an impact on the machined surface image in relation to two-sided one. It was because the halogen two-sided lighting created the dominant image texture. In this way this kind of surface illumination was applied for further analysis.

\section{Images of machined surface after turning}

Machined surfaces after turning were illuminated to expose their features (Table 2). The smoothest and the most reflective was the machined surface achieved when the modified cutting point was used. When the feed rate was small then the surface features revealed the feed marks like after the grinding. For greater feed rates the machined surface was still very smooth and reflective but tool run left more and better visible burrs. They are perfectly visible as light unequal ribbons set parallel along the traces.

Some disturbances are visible in uniform texture after the use of wiper geometry. Additional radii increased the contact length and cutting traces were smeared out over the surface. Darker spots reveal pits. In these regions the access for the light to the valleys was difficult because of steep slopes of the valleys.

Table 2: $\quad$ Machined surface image after turning.

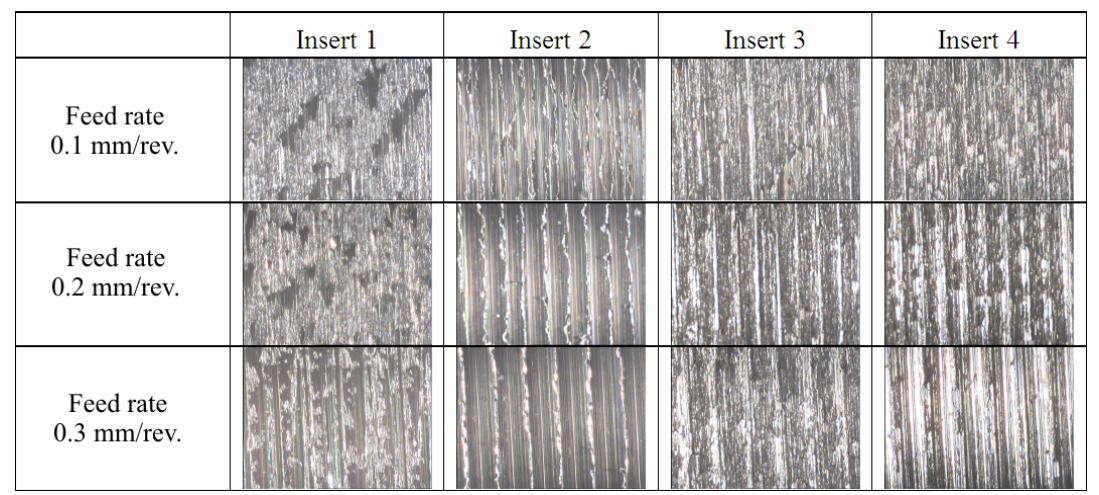

For rounded cutting points the machined surface features were the reflection of cutting tool geometry. When the feed rate was grater, the diversification of machined surfaces was more noticeable. For the small tool nose radius the machined surface image was characterised by a lot of light regions. Because of the two-sided lighting the slopes in a thread-like surface were perfectly 
distinguished. Only the bottom of the valleys, where the penetration of the light was difficult, was slightly darker.

For the cutting tool featuring greater tool nose radius the machined surface with the increase of feed rate showed less subsurfaces exposed to light. It contained a lot of smooth valleys between irregular remains after the tool pass. The features of this surface can in this way be located between the features of the surface for modified geometry and the surface created by the tool featuring the small tool nose radius.

\section{Final conclusions}

The paper considers the turned surface for different cutting parameters. Feed rate and tool geometry were the variables of the system. Three feed rates and four different tool wedge geometry were applied. The features $\mathrm{f}$ machined surfaces were distinguished and compared for the same cutting parameters.

When the wiper geometry tool wedge was applied, the machined surface was significantly different from the other surfaces. This surface was not typical for turned surface because the machined surface was also burnished by additional radii. These surfaces ware characterised by small roughness. Three-dimensional surface data revealed a lot of heterogeneities and discontinuities. In machined surface optical images these features were visible as dark ragged regions.

The other tool geometries (modified geometry, rounded cutting points with great and small tool nose radii) created directional machined surface, typical for turning operations. The comparison of surface roughness parameters and optical images enabled for the three geometries to be described more general. For the smallest tool nose radius the machined surface revealed the features of thread. It was rough and very directional. The increase of the tool nose radius made the decrease in surface roughness parameters. The machined surface was smoother. By applying tool with modified geometry in a way of artificial wear, the tool nose radius increased even more significantly. This new tool created machined surface of the smallest vertical parameters, very smooth and reflective.

\section{References}

[1] Grzesik W., Wanat T.: Surface finish generated in hard turning of quenched alloy steel parts using conventional and wiper ceramic inserts, International Journal of Machine Tools \& Manufacture 46, pp.1988-1995, 2006.

[2] Kukielka L.: The principals of engineering research (in Polish), PWN Warszawa 2002.

[3] Storch B., The issues of edge phenomena and monitoring in single-point turning (in Polish), Technical University of Koszalin Press, Monograph 124, 2006.

[4] Storch B.: Geometry of cutting part (in Polish), Patent no. PL 173536 B1, WUP Vol. 03, 1998.

[5] Thiele J.D., Melkote S.N.: Effect of cutting edge geometry and workpiece hardness on surface generation in the finish hard turning of AISI 52100 steel, Journal of Materials Processing Technology 94, pp. 216-226, 1999. 
104 Surface Effects and Contact Mechanics IX

[6] Zawada-Tomkiewicz A., Storch B.: Introduction to the Wavelet Analysis of a Machined Surface Profile, Advances in Manufacturing Science and Technology, Vol. 28, No 2, pp. 91-100, 2004.

[7] Zawada-Tomkiewicz A., Storch B.: Efficiency of turning process with the use of modified cutting points (in Polish). Cutting. High productivity. Editorship of Cichosz P. Wroclaw University Press, Vol. 1, pp. 205-212, 2007.

[8] Zawada-Tomkiewicz A., Storch B.: The Application of Image Processing Techniques in the Tool Wear Estimation, Computational Methods in Contact Mechanics VI, WITPRESS Southampton, pp. 201-210, 2003. 